\title{
Reflexões teórico-metodológicas acerca do futebol e fontes orais
}

\author{
Sérgio Settani Giglio* \\ ORCID iD 0000-0002-3190-0859 \\ Universidade Estadual de Campinas, Faculdade de Educação Física, Campinas, Brasil
}

\author{
Marcel Diego Tonini* \\ ORCID iD 0000-0002-9757-5593 \\ Pesquisador independente, Campinas, Brasil
}

\begin{abstract}
Resumo: A partir de entrevistas realizadas com jogadores de futebol brasileiros que atuaram no exterior, temos por objetivo discutir elementos referentes ao aspecto teórico-metodológico da História Oral. Desse modo, as relaçôes entre presente e passado, memória e história, lembrança e esquecimento são acionadas para contribuir com o entendimento da importância do método. Em seguida, buscamos diferenciar uma entrevista de História Oral de uma entrevista jornalística, bem como refletir acerca de quais são as contribuições de pesquisas que visam à produção de fontes orais quando se pensa o campo de estudos sobre esporte. Como conclusão, ressaltamos a importância da construção de novas fontes sobre futebol, do mesmo modo que este campo traz desafios de cunho teórico-metodológico para a História Oral.
\end{abstract}

Palavras-chave: Memória. Fontes orais. Atletas. Esporte. Futebol masculino.

\section{Theoretical-methodological reflections on football and oral sources}

Abstract: Based on interviews conducted with Brazilians football players who played abroad, we aim to discuss elements related to the theoretical-methodological aspect of Oral History. Thus, we work the relationship between present and past, memory and history, remembrance and forgetting are triggered to contribute to the understanding of the importance of the method. Next, we sought to differentiate an

Doutor em Ciências pela Escola de Educação Física e Esporte da Universidade de São Paulo. E-mail: ssgiglio@unicamp.br.

* Doutor em História Social pela Universidade de São Paulo (USP), com orientação do Prof. Dr. José Carlos Sebe Bom Meihy. E-mail: marceldt@gmail.com. 
Oral History interview from a journalistic interview, as well as to reflect on which are the contributions of researches that aim at the production of oral sources when thinking on the field of sport studies. As a conclusion, we emphasize the importance of building new sources on football, in the same way that this field brings theoretical-methodological challenges to Oral History.

Keywords: Memory. Oral sources. Athletes. Sport. Men's football.

\section{Introdução}

"Aí cheguei lá, [...] abriu a porta do aeroporto, aquele ar quente, aqueles caras vestidos todos de branco, aquelas mulheres todas tampadas, aí eu: 'Aonde eu tô, cara?'” (Wendel Prates, 2013). Foi assim que Wendel Prates, o Nenê, relatou sua chegada ao Catar. Sem contrato, sem falar a língua, à mercê de alguém que pudesse ajudá-lo com o idioma, sem dinheiro, desembarcava em um país desconhecido em busca do sonho de ser jogador de futebol profissional.

Ser um jogador de futebol, se tornar um ídolo de seu clube, atuar no exterior e, consequentemente, ter fama e ser reconhecido mundialmente talvez seja um dos desejos dos muitos meninos que sonham em ser profissionais da bola. Em que pese as histórias contadas, especialmente, pela televisão serem acerca de personagens que obtiveram sucesso em sua trajetória profissional, também se sabe que esse não é o cenário para a maioria dos atletas de futebol, conforme destacamos acima.

Independentemente da fama que tenham obtido por meio dessas experiências, podemos dizer que as histórias se assemelham pelas situaçóes vividas na condição de estrangeiro. O ex-jogador Evair, por exemplo, atuou pelo Atalanta da Itália em 1988 e assim relatou o que as pessoas perguntavam sobre o Brasil: "Ah, e os macacos, lá? Atravessam a rua? Como é que vocês convivem?" (Evair Aparecido Paulino, 2013).

Durante dois anos, essas histórias foram registradas pela pesquisa "Memórias de Boleiros" por meio do Núcleo Interdisciplinar de Pesquisas sobre Futebol e Modalidades Lúdicas (Ludens) da Universidade de São Paulo, em parceria com o Museu do Futebol e o portal Ludopédio. A nossa proposta era reunir e registrar as histórias de vida de jogadores de futebol masculino e de integrantes das comissóes técnicas que haviam atuado no exterior. Ao todo, foram realizadas dez entrevistas com futebolistas de renome nacional e internacional, com exceção de um deles (Nenê), que, embora não tenha se profissionalizado, também atuou no exterior.

A história de Nenê é ao mesmo tempo muito parecida com a de grande parte dos atletas brasileiros que anualmente emigram em busca de uma vida melhor. Uma minoria, tanto aqui quanto no exterior, terá acesso ao mundo da fama, do dinheiro e isso significa que jogaráo, em grande parte, pelos principais clubes das ligas de futebol mais ricas do planeta. Nove dos dez futebolistas que entrevistamos jogaram em clubes 
de médio e grande porte no exterior. Náo pretendemos reforçar os discursos que pensam o futebol como sinônimo de sucesso. Queremos, antes de tudo, encontrar nas histórias contadas os elementos comuns e a dimensão humana das narrativas que, no mundo do futebol, evocam as incertezas, as dificuldades e os desafios em atuar em alto rendimento em clubes do exterior. Buscamos, portanto, os elementos da memória e do esquecimento para compor um quadro teórico de análise.

Desse modo, neste texto, pretendemos avançar no debate sobre memória e esquecimento, aprofundando tanto a discussão teórico-metodológica quanto as possibilidades de usos da História Oral no desenvolvimento de pesquisas no campo. Para tanto, deter-nos-emos na descrição do projeto coletivo "Memórias de boleiros" e utilizaremos, sobretudo, alguns trechos de entrevistas realizadas para a discussáo em torno do gênero histórias de vida. Nosso objetivo é, portanto, realizar reflexóes e contribuir, modestamente, para a historiografia.

Isto posto, comecemos, pois, com algumas perguntas que permitiráo refletir sobre o método da História Oral (HO): Quais as diferenças entre entrevistas do jornalismo esportivo e as de $\mathrm{HO}$ ? O que pretendemos ao entrevistar atletas por meio da metodologia da HO? Como pode ser definido o grupo de pessoas entrevistadas em $\mathrm{HO}$ ? $\mathrm{O}$ que as entrevistas nos mostram e nos ensinam sobre teoria e método da $\mathrm{HO}$ ? Que contribuiçôes as memórias de atletas/futebolistas podem trazer às pesquisas da HO? De que maneira elas contribuem para o debate acadêmico? Enfim, de que maneira a $\mathrm{HO}$ contribui para o campo de estudos sobre esporte?

Para responder a essas perguntas, é preciso entender os caminhos percorridos por nossa pesquisa. Ao optarmos pela história de vida, buscamos acessar uma série de memórias e experiências em geral pouco investigadas por estudiosos do campo esportivo. Isso pode ser verificado quando se recorre à história do futebol e se percebe que existe uma história que é considerada "oficial". Com o registro de novas entrevistas com jogadores consagrados, ${ }^{1}$ nossa intençáo era ir muito além do que o jornalismo esportivo tem recorrentemente produzido. Em que pese alguns discursos estarem cristalizados por meio de uma repetição de histórias contadas, nosso desafio era, portanto, elaborar perguntas diferentes das que eles já haviam sido interpelados e estimular falas sobre temas pouco abordados. Ao dar-lhes ouvidos, tentamos torná-los protagonistas de suas próprias histórias ao invés de reféns de uma narrativa construída em cima de questóes batidas. No limite, a intenção era tornar pública uma gama de histórias, memórias e experiências até então desconhecidas.

Desse modo, o ponto de partida comum os colocava em uma dimensão macro que envolve a construçáo do sonho de ser jogador de futebol, o sucesso em sua trajetória e o reconhecimento também no exterior. A essa condição macro, aqui entendida como

1 Nas palavras do jogador Denilson, um de nossos entrevistados, o jogador consagrado é aquele que consegue deixar seu nome na história do clube (Denilson Pereira Neves, 2014). 
o desejo, acopla-se uma outra dimensão, a micro, materializada por meio de sua experiência particular que, por consequência, os colocaram em contato com pessoas, clubes e países específicos. Por meio dela, pode-se questionar algumas generalizaçóes produzidas por meio das palavras - e por que não de nossos vícios linguísticos? ocultam certas dimensôes heterogêneas.

Assim, jogar no exterior não pode ser vista como um lugar comum, como algo homogêneo. Deve ser compreendido em suas particularidades. O mesmo vale para se pensar o país e, de modo ainda mais particular, o clube. Clubes de um mesmo país não funcionam da mesma maneira, por mais que possamos encontrar semelhanças também encontraremos particularidades.

Nessa tarefa de produzir novas narrativas, a escolha metodológica foi pela História Oral. Não somente por sua potencialidade em acessar as histórias "ainda não contadas" por aqueles atletas, mas também pela possibilidade em construir um diálogo efetivo com o referencial teórico das Ciências Humanas. ${ }^{2}$ Por meio da história de vida, buscamos registrar memórias, histórias e experiências dos sujeitos mencionados, além da criação de um banco audiovisual com as entrevistas realizadas, de modo a constituir um acervo para preservar a elaboraçáo de tal memória, quer se refira, de modo restrito, à carreira dos mesmos, quer, de modo geral, ao futebol brasileiro praticado por homens.

A proposta, portanto, deste artigo é discutir do ponto de vista teóricometodológico fontes não escritas, bem como refletir sobre a relação entre o passado e o presente como lugar de construçáo da narrativa.

\section{Partindo do presente para acessar o passado}

O processo de entrevista em História Oral é sua condição essencial. Será por meio dela, isto é, através da gravação da fala da pessoa durante um encontro entre entrevistador e entrevistado, que podemos produzir importantes fontes e, por conseguinte, conhecimento. Aqui a fonte não é apenas a oral, pois conforme ressalta Portelli (2010, p. 20), "o relato da história não é um fim em si mesmo. No que diz respeito ao entrevistador, visa à produçáo de um outro texto: uma fita, um vídeo, e, principalmente, um texto escrito, um livro". Essa dimensáo colocada por Portelli abre alguns pontos para análise.

2 Esta não é a primeira vez que a relação entre Esporte e Fontes Orais é nosso objeto de estudo (Giglio, 2013, 2018; Tonini, 2011, 2016, 2020). Na ocasião da publicação do capítulo "História oral e futebol" (Giglio; Tonini, 2021), elaboramos um texto introdutório voltado para professores da rede pública de ensino. Em linhas gerais, versamos sobre a formação desse campo no Brasil, caracterizamos a coletividade dos "boleiros", trouxemos algumas experiências de pesquisa e discutimos brevemente sobre memória e esquecimento. A intenção, em suma, era trazer o futebol para a sala de aula e oferecer os procedimentos metodológicos da História Oral para trabalhar com ele. 
Em primeiro lugar, é preciso deixar claro que entrevistar não significa fazer História Oral. Como se sabe, desde a antiguidade historiadores utilizavam relatos orais de testemunhas a fim de descrever e verificar fatos históricos passados. Já no século XIX, sociólogos, antropólogos e outros estudiosos das Ciências Humanas, também se valeram e desenvolveram técnicas de pesquisa baseadas na aplicação de questionários ou no uso de entrevistas para investigar uma dada realidade social. Somente a partir da metade do século XX que o campo da $\mathrm{HO}$ foi fundado, definido e desenvolvido em termos teóricos e metodológicos. Concomitantemente, o jornalismo, inclusive o esportivo, passou a registrar, destacar e difundir memórias e histórias. O avanço tecnológico da eletrônica e dos meios de comunicação tornou isso possível.

Do ponto de vista acadêmico, contudo, a entrevista náo se trata apenas de uma produção bruta em termos de um material. A gravação em si é importante, entre outras razóes, por possibilitar a construção de análises posteriores acerca da narrativa oral. Portanto, uma mesma entrevista pode ter fins diferentes. Em nosso caso, para o Museu do Futebol a entrevista tinha a finalidade de constituição de um acervo que ficaria disponível para consulta. Para o portal Ludopédio, ${ }^{3}$ foram realizadas ediçóes de modo a compor o espaço da divulgação científica em que foram suprimidas as repetiçóes e frases incompletas que são cortadas por outros assuntos que surgem durante a narrativa. Para os pesquisadores envolvidos, as entrevistas foram em alguns casos analisadas em suas respectivas pesquisas acadêmicas individuais e em publicaçóes posteriores.

Sem dúvida, há distintas formas de se proceder ao longo de uma entrevista de $\mathrm{HO}$, haja vista que cada pesquisador é capaz de avaliar qual se apresenta mais apropriada conforme o tipo de entrevista adotado. Em nosso caso, não obstante, optamos por uma mediação sutil. Ressaltá-la tem por finalidade buscar alguns caminhos que podem ter ficado para trás da narrativa em detrimento de histórias mais significativas. Conforme destaca Portelli (2001, p. 18), "[...] a narrativa da fonte pode ser vista sempre como uma resposta para a questão inicial do historiador”. Logo, a mínima ação do entrevistador acaba interferindo nos rumos da entrevista, desde os contatos prévios, nos quais se explicam os motivos para um encontro cuja narrativa será gravada, e em que um ou mais temas de interesse são verbalizados pelo pesquisador. Durante a gravação, em especial, entendemos que essa "interferência" do pesquisador deve ser precisa de modo a não atrapalhar a construção do fio narrativo do entrevistado.

Cabe destacar que essa interaçáo entre entrevistador e entrevistado tem que ser entendida em sua bipolaridade dialógica e intersubjetiva (Passerini, 2011), escapando de uma armadilha positivista que colocaria um interrogador e um depoente, um pesquisador e um informante, um observador e um observado, ou mesmo um sujeito e um objeto. É preciso borrar essas fronteiras, pois a História Oral é produzida por meio

O site Ludopédio surgiu em 2009 com o objetivo de reunir e divulgar a produção científica sobre futebol. Com o tempo, passou também a produzir novos conteúdos sobre o tema. Disponível em: www. ludopedio.org.br. Acesso em: 20 set. 2021. 
da interação entre ambos, "entre-vistas" (Ferreira, 1998a), em uma relação, sem que seja necessário pontuar esse lugar. Ainda assim, deve-se atentar para as relaçóes de poder inerentes de lado a lado, quer seja a do acadêmico em relaçáo a uma pessoa iletrada, quer seja a de uma personalidade em relação a um pesquisador.

O desafio de borrar as fronteiras parece simples à primeira vista, porém esses lugares sáo definidos de modo implícito ao primeiro contato com o entrevistado. Em nosso caso, não entrevistamos pessoas próximas de nosso círculo de atuação. Entrevistamos, em sua maioria, pessoas públicas que não nos conheciam. Tínhamos que, ainda na condição de futuros entrevistadores, explicar os objetivos da pesquisa, as entidades envolvidas, se a entrevista seria gravada em vídeo ou somente em áudio. Como a produção visava um acesso público aos materiais da entrevista, isso também era explicado no contato inicial. Ter o Museu do Futebol como parceiro facilitou o aceite das entrevistas. Se éramos pessoas desconhecidas, o local da entrevista, Estádio do Pacaembu, se tratava de um espaço público e, mais do que isso, um "lugar de memória" (Nora, 1993). Permitia, portanto, não apenas quebrar a desconfiança inicial, mas reforçar, em boa parte, a credibilidade e, sobretudo, rememorar histórias ali mesmo vividas. A possibilidade de fazer com que a própria narrativa se constituísse em acervo da principal instituiçáo museológica de futebol no país pode ter sido um facilitador para a viabilidade dos encontros.

Apesar disso, houve um caso em que um de nossos entrevistados aproveitou para questionar as escolhas do Museu do Futebol sobre quais histórias contar. O exjogador Careca começou a entrevista pontuando seu descontentamento por não estar contemplado na exposição de longa duração da instituição museológica:

[...] mas já vai, assim, um protesto. Poderiam ampliar os jogadores diferenciados, deixaram muita gente fora ali. [...] Muitos jogadores que tiveram um passado brilhante também, que ali não estão entre os melhores, que serviram à seleção brasileira. Muitos jogadores ficaram de fora, eu fui um deles. (Antônio de Oliveira Filho, 2012).

O ponto de partida dessa entrevista trouxe maiores desafios, pois, ao mesmo tempo em que se disponibilizou a conversar e compartilhar a sua história, questionou logo na abertura de sua fala os critérios eleitos pelo Museu do Futebol para selecionar as histórias que ali seriam retratadas. ${ }^{4}$

Um aspecto importante das entrevistas em $\mathrm{HO}$ é que boa parte delas é produzida para se transformar em texto (Portelli, 2001). Em nossa pesquisa, essa condição também se fazia presente, a transcrição da entrevista seria um dos materiais produzidos. Porém, não queríamos nos limitar aos textos, mas também produzir um material em vídeo para que ficasse disponível como acervo do projeto. A forma de nossa produção audiovisual

4 Sobre o entendimento do Museu do Futebol como espaço de memória, sobre sua história e críticas, conferir: Moraes (2009), Azevedo e Alfonsi (2010), Wenzel e Munhoz (2012) e Toledo (2019). 
estava focada no entrevistado, afinal era a história dele que queríamos ouvir e registrar. Com isso, a câmera ficava estática no entrevistado, e os entrevistadores revelavam-se apenas pelo áudio.

A esse fato, soma-se um outro importante. Será que diante da gravação por vídeo teríamos algum tipo de desconforto ou de inibição por parte dos entrevistados? No caso de nossos entrevistados, pelo fato de a maioria ter tido uma carreira no futebol profissional espetacularizado (Damo, 2007), a dinâmica da gravação em vídeo não foi um impeditivo para compartilhar suas narrativas ou tampouco criou qualquer tipo de constrangimento. Mais do que acostumados ao aparato tecnológico e à grande equipe de produção, ${ }^{5}$ a impressáo que tivemos é que, aos olhos deles, isso conferia uma maior seriedade e valor ao registro, bem como um reconhecimento por sua importância dentro da história do futebol brasileiro. Eventualmente, essa atenção toda pode ter sido até desejada por alguns deles, como uma espécie de revivescência dos áureos tempos de atleta.

Talvez o maior exemplo disso tenha se dado no contato com um dos entrevistados. Por várias vezes, ao invés de ele simplesmente negar a concessão do relato, dizia-nos estar "em uma reuniâo de showball”, sugerindo procurá-lo em um momento futuro. Após entrevistarmos o ex-lateral Zé Maria, solicitamos indicaçóes, como sempre, tendo sido citado aquele futebolista. Ao dizermos que ele se mostrava sempre ocupado, o futebolista debochou: "Ele não faz nada o dia inteiro" (José Marcelo Ferreira, 2013). Fato é que, quando uma funcionária do Museu do Futebol entrou em contato com tal jogador, ele aceitou o convite e ofereceu uma das entrevistas mais entusiasmadas e longas que realizamos nesse projeto.

As histórias de vida permitiram aos jogadores de futebol relembrar o processo pelo qual passaram até chegarem a um clube do exterior e, em alguns casos, até à seleçáo brasileira. Esse rememorar, embora tenha partido do passado, foi construído a partir da visão de mundo que esse atleta possui no presente. Conforme argumenta Rubio (2006, p. 21-22), por meio das histórias de vida o pesquisador tem acesso ao modo como o entrevistado fala, pode capturar os mais sutis detalhes de suas expressóes no momento da narrativa, enfim, "ter acesso aos conteúdos de uma vida que pode ser tomada como individual, mas que carrega consigo os elementos do momento histórico e das instituiçôes com os quais manteve relação".

No caso específico de nossos entrevistados, a dimensão do momento histórico e a vivência em um ou mais clubes guiam suas rememoraçóes e contaçóes de histórias. A condiçáo de estar no exterior é permeada por uma agremiação de futebol e uma cidade. Embora as narrativas possam apontar que os entrevistados jogaram no exterior, a pesquisa acadêmica deve tensionar e especificar sobre qual local falam, pois fazer

5 Com uma ou outra exceção, a maioria das entrevistas contou com pelo menos dois entrevistadores e duas outras pessoas responsáveis pelo registro audiovisual, sonoro e fotográfico. 
referência a um continente, como Europa ou América do Sul, é muito amplo. Tomar a Europa, por exemplo, como algo único é um ponto de partida que pode comprometer a análise. Há um excerto da narrativa de Zé Maria que elucida com objetividade e clareza essa discussão, sobretudo por tratar de distintas culturas dentro da Itália: "Essas coisas fazem a diferença, fui aprendendo um pouquinho de cada regiáo. Eu treinei na Calábria, joguei em Perugia, Milão e Parma. São quatro culturas completamente diferentes dentro do mesmo país" (José Marcelo Ferreira, 2013).

Sobre essa experiência de estar no exterior, não podemos desconsiderar a condição do "rodar" proposta por Rial (2008). A circulação na curta carreira futebolística acaba sendo uma condiçáo de grande parte dos jogadores. Isso foi destacado como um valor pelo ex-jogador Amoroso, que se valeu de um verbo com significado semelhante "passar": "eu passei por Japão, Itália, Alemanha, Espanha e Grécia, né, foram cinco países [...]" (Márcio Amoroso dos Santos, 2013). A pergunta ou a reflexão que deve ser feita pelo pesquisador é: Sobre qual Japão você/ele fala? Em que época viveu lá? Por quanto tempo viveu? Jogou por qual clube? De qual divisão do futebol local esse clube participava? Com quem conviveu? Mais do que buscar uma dimensão espacial e temporal mais específica, convém compreender as experiências vividas, os significados atribuídos, as essencializaçóes culturais representadas e todo um conjunto de manifestaçôes (verbalizadas ou não) que são da ordem do subjetivo. De cada ponto da fala, é possível abrir novas perguntas, reflexōes e "janelas" que dizem tanto sobre as idiossincrasias desses indivíduos como de seu coletivo.

As narrativas de uma entrevista em $\mathrm{HO}$ fazem com que passado e presente estejam contemplados na história contada. Sobre essa relaçáo do tempo na narrativa que coloca em intersecção o passado e o presente, corroboramos com a ideia de Ferreira (2002, p. 321), quando afirma que a relação entre história e memória permitiu aos historiadores repensar as conexóes entre passado e presente, possibilitando que o estudo acerca dos conhecimentos do passado pudesse ser utilizado pela história do tempo presente. Nesse jogo de relaçôes, a autora destaca que: "A memória é também uma construção do passado, mas pautada em emoçóes e vivências; ela é flexível, e os eventos são lembrados à luz da experiência subsequente e das necessidades do presente".

Sob a perspectiva de Meihy e Holanda (2007, p. 72), "a história oral como metodologia implica formular as entrevistas como um epicentro da pesquisa". Dentro desse entendimento, a $\mathrm{HO}$ orienta toda a elaboraçáo de um projeto, no qual as fontes orais compóem o corpus documental central de uma pesquisa. É a partir do conjunto das narrativas orais que são identificados problemas a serem refletidos, podendo ou não dialogar com outras fontes e argumentos estabelecidos pela literatura acadêmica. Para essa linha transdisciplinar, memória e identidade são as matérias-primas da $\mathrm{HO}$ e permitem a caracterização de uma dada comunidade.

Ter acesso às narrativas orais no sentido de obter "uma outra história" ou a "história vista por outro ângulo" é fundamental para não ficarmos restritos à versão dos 
fatos que é considerada como oficial ou hegemônica dentro da historiografia. Embora Magnani (2009, p. 135) escreva sobre etnografia, é possível relacioná-la com a História Oral quando analisa a presença do pesquisador. Desse modo, entende:

[...] que o pesquisador entra em contato com o universo dos pesquisados e compartilha seu horizonte, não para permanecer lá ou mesmo para atestar a lógica de sua visão de mundo, mas para, seguindo-os até onde seja possível, numa verdadeira relação de troca, comparar suas próprias teorias com as deles e assim tentar sair com um modelo novo de entendimento ou, ao menos, com uma pista nova, não prevista anteriormente.

Nessa mesma linha, Oliveira (2006, p. 34) ${ }^{6}$ propóe acessar a "sociedade e a cultura do outro 'de dentro' por meio do exercício de olhar e de ouvir", ou no dizer de Magnani (2002, p. 18) deve-se olhar "de perto e de dentro". Nessa perspectiva, conforme as entrevistas foram realizadas, pudemos perceber o quanto as histórias individuais estavam conectadas com o momento histórico vivido pelos atletas. As entrevistas transformaram-se, portanto, em um importante acesso para "[...] eventos desconhecidos ou aspectos conhecidos de eventos conhecidos: elas sempre lançam nova luz sobre áreas inexploradas da vida diária de classes não hegemônicas" (Portelli, 1997a, p. 31).

Quando entrevistamos Betão em fevereiro de 2014, por exemplo, a Ucrânia passava por uma onda de manifestações e distúrbios civis que levaram à deposição do entâo presidente, Viktor Yanokóvytch, à instauraçấo de um governo provisório - o qual náo foi reconhecido pela Rússia - e, consequentemente, a conflitos militares na regiáo leste. Evidentemente, o ex-zagueiro, que atuara no país entre 2008 e 2013, abordou o tema por conta própria e nos apresentou suas experiências pessoais à luz do que ocorria dentro do futebol:

Havia uma divisão política no futebol também: o Dínamo de Kiev é mais para o lado ucraniano; o Shakhtar Donetsk, mesmo estando na Ucrânia, é mais voltado para o lado russo. Tanto é que no oeste do país, Lviv - que é perto da Polônia -, Kiev e outras cidades, as pessoas falam ucraniano, porém no leste não se fala. Donetsk, por exemplo, que é a regiáo dos minérios, ficou mais sob domínio dos russos. Com tudo isso, já percebia que existia um racha, o qual influenciava muito no futebol. Quando jogam Shakhtar e Dínamo, não é só uma rivalidade do futebol, é também política. (Ebert Willian Amâncio, 2014).

Pelo fato de termos, em grande parte, entrevistado pessoas que possuem uma história pública, pelo fato de terem sido jogadores de clubes importantes do futebol

6 Para o autor, o trabalho do antropólogo envolve: olhar, ouvir, escrever. 
nacional e internacional, pelo fato de terem jogado pela seleção brasileira e/ou conquistado títulos, suas histórias esportivas acabaram sendo registradas em diversos lugares. A importância para o mundo acadêmico das entrevistas realizadas não está na busca pela validação das informaçôes compartilhadas, mas no acesso ao discurso, a versôes "outras", subjetivas, e a essa construção feita em primeira mão, protagonizando a própria voz e valorizando-o enquanto sujeito.

Narrativas similares podem ser encontradas em jornais, programas de televisão, páginas especializadas em futebol, entrevistas em rádio, e em acervos museológicos. Neste caso, acessaremos entrevistas a partir de uma segunda ou até mesmo terceira mão, pois nem sempre estão explícitos para quem acessa tais conteúdos, os objetivos e as condiçốes de produção das narrativas. Sendo a entrevista o epicentro da pesquisa, é em relaçáo aos objetivos do problema de pesquisa que as pessoas foram escolhidas para as entrevistas. Formaram, com isso, uma "comunidade de destino" (Bosi, 2007; Meihy, 2005) que se referia a esse problema de pesquisa.

\section{Memórias que contam histórias}

Se buscarmos outras entrevistas de nossos entrevistados, nós poderemos encontrar narrativas muitas similares em que há pequenas mudanças sob o ponto de vista linguístico, mas nas quais são mantidas a ordem dos fatos e até mesmo os detalhes contados. Também poderemos encontrar diferentes narrativas dessa pessoa para os mesmos fatos. Como ficaria, entâo, a relaçấo entre passado e presente na construçáo da narrativa?

Para explicar essa condição, pensamos na narrativa enquanto memória e na memória da narrativa. Para quem possui uma narrativa mais fechada, que pode ser encontrada em outros lugares e que não apresenta variaçóes significativas, pode-se explicar que assumem a narrativa como memória. Isso significa dizer que a construção de sua memória corresponde aos fatos que exatamente quer contar, ou seja, não abre espaço para que diante de uma nova pergunta ou estímulo possa rever suas lembranças do passado. A memória da narrativa, por sua vez, seria a abertura para a dimensáo dialógica da entrevista, ao permitir acessar e produzir novas narrativas sobre o passado.

É importante destacar que essas duas dimensôes não estão dadas, anunciadas ou são explícitas durante a entrevista. Um indício de como funciona essa condição poderá ser percebida diante das perguntas e inferências feitas por quem é o entrevistador, pois diante da resposta será possível saber se o entrevistado aceitou o convite para construir de outra maneira sua memória ou se continuou a responder do mesmo jeito que havia começado, conforme uma cristalização já dada. A essa recorrência Pollak (1992) chamou de "invariante" e, mesmo que outros acontecimentos tenham feito parte da 
vida da pessoa, a repetição indica que alguns fatos prevalecem em detrimento de outros, por ser a memória algo construído a partir de um trabalho de organização.

As histórias contadas não estão isoladas de um contexto mais amplo. Halbwachs (2006, p. 80) oferece subsídios para entendermos como a memória coletiva pontua a nossa memória individual: “[...] é na memória histórica que temos de nos basear. É através dela que esse fato exterior à minha vida vem assim mesmo deixar sua impressáo tal dia, tal hora, e a vista dessa impressão me fará recordar a hora ou o dia [...]”. Afirma o autor que sempre nos relacionamos com duas memórias: a nossa, que é individual, e a coletiva, que é construída a partir da relação com a sociedade. Santos $(2013$, p. 57) ressalta que Halbwachs considera a memória social não sendo uma expressão dos fatos acontecidos no passado, "[...] mas uma construçáo coletiva do passado realizada pelos indivíduos de determinada coletividade".

Cada entrevistado de nossa pesquisa narrou a sua trajetória, selecionou os fatos, falou de algo que é particular, individual, apresentando uma narrativa de cunho autobiográfico. No entanto, esse relato oral sobre a própria vida pessoal e esportiva necessariamente apareceu vinculado aos acontecimentos mais amplos de sua carreira e dos clubes pelos quais jogou, com e contra quem atuou. Essa perspectiva, fica evidente na fala de Evair quando analisa se havia feito um bom negócio ao trocar o Guarani de Campinas pela Atalanta da Itália:

Não, eu nunca achei, eu nunca achei porque, apesar de o salário ser muito melhor, mas eu ia ter uma mudança muito grande, como foi. Mas não deixava de ser um grande desafio também. O Atalanta estava subindo da segunda pra primeira divisão num futebol de Maradona, Careca, Van Basten, Gullit, Rijkaard, Baresi... Então, a gente ia ter que enfrentar toda essa gente, e eu não tinha toda a experiência pra isso. (Evair Aparecido Paulino, 2013).

Dito de outro modo, essa memória foi conectada a outros fatos e, mais do que isso, a outras memórias, que, entrecruzadas, revelam experiências comuns. Seguindo essa linha, Pollak (1992) afirma que existem três elementos constituintes da memória: os acontecimentos, as pessoas e os lugares. É por meio da intersecção deles que as narrativas apresentadas faziam referência. Nesse sentido, a história individual está associada à memória coletiva, pois a sua experiência está sempre conectada a um contexto mais amplo, sendo chamado por vários autores de memória coletiva. Acerca desse tema, Ortiz (2000, p. 75) afirma que os acontecimentos sempre acontecem em um território, nação, cidade, bairro. Por isso, "A lembrança é possível porque o grupo existe, o esquecimento decorre de seus desmembramentos. Entretanto, para ser vivificada, a memória necessita de uma referência territorial, ela se atualiza no espaço envolvente".

Em síntese, a memória é um trabalho sobre o tempo vivido, relacionado com a cultura e o indivíduo. Quando Bloch (2001) afirma que o objeto de estudo da história 
é analisar os homens no tempo, o autor coloca no centro do debate que o interesse está no modo como aconteceram os processos relativos aos fatos investigados e afirma que nessa relação temporal o entrevistado irá partir do presente para analisar o passado. Portanto, por meio das histórias de vida dos atletas, ficou evidente a articulação entre o presente e o passado, tendo claro que o passado é algo que não se modificará mais, o que se altera é o conhecimento em relaçáo a ele. E esse conhecimento em relaçáo ao passado pode ser interpretado como o "tempo vivido", nas palavras de Bosi (2003). Djalminha, ao ser indagado se faria tudo de novo em sua vida, já no fim da entrevista, não deixou dúvidas, porém indicou como a experiência que o tempo lhe deu modificaria algumas vivências: "Claro, com certeza, com certeza... Agora, com a experiência mudaria um negocinho aqui, outro ali... Pô! Iria ajeitar um pouquinho, mas faria tudo de novo com certeza." (Djalma Feitosa Dias, 2012).

A questão desencadeadora da narrativa, de todo modo, não era uma pergunta, mas um convite para o sujeito contar sua história. A reação subsequente já indica pontos para a análise. Isso porque alguns iniciaram suas narrativas pelos pais, local e data de nascimento; outros iniciaram por sua iniciação esportiva, uma vez que já havia sido anunciada a intençáo da pesquisa sobre sua experiência por ter jogado no exterior; houve ainda aqueles que, mesmo tendo recebido essa informação, uma vez mais questionam: "Minha história de vida ou minha história de vida no esporte?" Não bastasse isso, a organizaçáo do discurso também remete a outras possíveis interpretaçóes, uma vez que ele pode se dar de forma linear ou cíclica.

Como náo se tratava de destrinchar previamente sua vida, pelo contrário, queríamos conhecê-la em detalhes por meio da fala do entrevistado, havia a possibilidade de algum fato de sua vida não ser dito. Aquilo que é silenciado, omitido ou apresentado de maneira confusa revela o modo como o fato histórico foi apropriado pela pessoa (Bosi, 2003). A respeito desses elementos, Pollak (1989) completa que o não dito está relacionado diretamente com uma estrutura vigente, oficializada, que impede ou faz com que seja apresentada de inúmeras formas, dependendo do local/momento; o entrevistado fala em detalhes ou ao falar omite nomes de terceiros, enfim, conforme afirma o próprio autor (1992), a memória é seletiva.

Zé Maria, por exemplo, ao rememorar as mudanças de sua vida ao se profissionalizar, revelou ter tido uma adolescência interrompida. As pausas na fala deixam no ar sentimentos e situaçôes que de uma hora para outra não mais vivenciou:

Como eu falei antes, eu tive que amadurecer muito rápido. Não tive uma adolescência normal... mas não reclamo daquilo que vivi. Lógico, eu falo sempre pra minha esposa que sentia falta de conviver com os amigos da escola. Quando eu estudava lá no Brás, tinha aquelas coisas de cabular aula e ficar todo mundo na frente da escola brincando, batendo papo. Isso de repente sumiu da minha vida... (José Marcelo Ferreira, 2013). 
Como a memória irá selecionar fatos localizados no tempo e no espaço a partir de eixos comuns (Bosi, 2003) não saberemos se o fato vivido foi realmente esquecido pelo entrevistado, ou se ele o omitiu/censurou por não querer citar nomes ou envolver terceiros. O tempo entre o primeiro contato e a realizaçáo da entrevista permitiu ao entrevistado pensar sobre sua trajetória no futebol e reconstruir alguns fatos.

Segundo Halbwachs (2006, p. 32):

Não basta que eu tenha assistido ou participado de uma cena em que havia outros espectadores ou atores para que, mais tarde, quando estes a evocarem à minha frente, quando reconstituírem cada pedaço de sua imagem em meu espírito, esta composição artificial subitamente se anime e assuma figura de coisa viva, e a imagem se transforme em lembrança. É comum que imagens desse tipo, impostas pelo meio em que vivemos, modifiquem a impressão que guardamos de um fato antigo, de uma pessoa outrora conhecida. Essas imagens talvez náo reproduzam muito exatamente o passado, o elemento ou a parcela de lembrança que antes havia em nosso espírito talvez seja uma expressão mais exata do fato - a algumas lembranças reais se junta uma compacta massa de lembranças fictícias. Inversamente, pode acontecer que os testemunhos de outros sejam os únicos exatos, que eles corrijam e rearranjem a nossa lembrança e ao mesmo tempo se incorporem a ela.

É preciso considerar o grande número de jogos em que cada atleta de futebol atuou. A sucessão de partidas dificulta, sem dúvida, a retenção de informaçóes a respeito de sua participação em determinado momento. Talvez, também, o "esquecimento" seja por conta de alguma derrota ou de um desempenho diferente do que se esperava dele, e isso faz com que, ao falar de suas experiências, eles não as coloquem como algo de fato significativo dentro do todo ou em comparaçáo com outros fatos.

Quando convidamos os entrevistados para contar sobre sua história de vida, nesse trabalho de rememorar o que foi vivido pode haver sobreposiçôes entre o que foi vivido e revivido, seja por meio das inúmeras vezes em que contaram suas histórias, seja, no caso dos atletas de futebol, pelo quanto assistiram e/ou leram sobre sua própria trajetória. A narrativa contada é, no fundo, esse mosaico entre o que a pessoa se recorda da sua experiência e do que foi incorporado à sua memória após a competiçáo. A essa mistura Portelli (1997b, p. 17, grifos no original) ressalta que "cada pessoa é um amálgama de grande número de histórias em potencial [...]". Em dado momento na narrativa de Zé Maria, ele relembrou a derrota sofrida pelos brasileiros para os nigerianos na semifinal dos Jogos Olímpicos de Atenas, em 1996, e retratou a tristeza individual e coletiva:

Já o terceiro gol da Nigéria foi de escanteio, que o Kanu cabeceou e o Dida saiu e não pegou. Eu fui controlar a bola, que normalmente bate na grama e sobe, mas ela bateu e ficou, passando embaixo do meu pé. A derrota para a Nigéria é um fato pra nãooo... relembrar, mas relembro o tempo todo. [...] Foi uma pena... nós tínhamos realmente tudo pra ganhar aquele torneio. [...] Estava 3 a 1? Então, tínhamos que 
ter feito 5 a 1 . Talvez nos acomodamos com aquele resultado... Eu me lembro até hoje como foi e acredito que todos jogadores que estavam naquele time também. (José Marcelo Ferreira, 2013).

Para Halbwachs (2006), isso se refere ao "quadro social da memória", pois muito do que se lembra é fruto daquilo que se sobrepôs, enquanto imagem, ao que ela viveu, pelo simples fato de que o exercício de relembrar, conforme dito anteriormente, é feito a partir do presente. Segundo o autor, as lembranças se adaptam às percepçóes do presente, colocando-nos diante de diversos testemunhos.

Se a memória será acessada a partir dos estímulos, interesses e necessidades do presente, o olhar do entrevistado será influenciado por tudo aquilo que ele viveu após o evento que quer contar. Santos (1998, p. 161) esclarece essa situaçáa: ${ }^{7}$

Encontro-me diante de um computador escrevendo e reescrevendo frases que jamais me deixam completamente satisfeita com seu sentido. Eu faço e refaço estas frases e chego à conclusão de que por mais que eu escreva, não consigo expressar completamente o que penso. $\mathrm{O}$ resultado é que eu escolho a melhor frase. $\mathrm{O}$ mesmo acontece com a memória. Quando eu me lembro de um evento do passado, o faço por meio da reconstrução de uma série de imagens fragmentadas e de um conhecimento acumulado a partir de experiências já vivenciadas. No momento exato em que expresso o passado sob a forma de imagem reconstruída, tal como a frase escolhida, dou ao passado uma localização específica no tempo e no espaço, e à memória, a rigidez que ela não possui; ou então obedeço à experiência adquirida ao longo dos anos, traindo a fidelidade ao passado. Como a imagem lembrada é sempre uma criação do presente, há sempre uma distância entre a imagem construída sobre o passado - em gestos, pensamentos ou açóes - e o passado, embora este último não esteja ausente da imagem do presente.

A dificuldade em relembrar alguns fatos ou a predileção do entrevistado em explorar outros aspectos de sua trajetória no futebol, ao menos enquanto detalhamento das informaçōes, pode ser entendida nas palavras de Halbwachs (2006, p. 34-35). Entre esses fatos, os que neles estavam envolvidos, em nós há uma descontinuidade, não apenas porque o grupo no seio do qual nós os percebíamos materialmente já não existe, mas porque não pensamos mais nele e não temos nenhum meio de reconstruir sua imagem.

Para Bosi (2003, p. 54): “O conjunto de lembranças é também uma construção social do grupo em que a pessoa vive e onde coexistem elementos da escolha e rejeiçáo em relação ao que será lembrado". Por isso conseguimos lembrar mais facilmente

7 A própria autora, em artigo posterior (2013), apresenta uma nova ideia a respeito da reconstrução do passado feita no presente. Entende que os indivíduos se lembram e se esquecem em complexas e contraditórias formas a partir de uma interação social. 
quando compartilhamos momentos vividos com pessoas importantes ou situaçóes significativas, mesmo que isso aconteça tantos anos depois. Na mesma medida, teremos dificuldades em nos lembrar de situaçóes corriqueiras que aconteceram recentemente pelo fato de não terem sido compartilhadas com pessoas importantes. Isso acontece porque a nossa memória se apoia na história vivida em que as lembranças coletivas se aplicam sobre as individuais; para que isso ocorra, contudo, é preciso que as lembranças individuais existam, pois, do contrário, a memória funcionaria no vazio (Halbwachs, 2006). E será nessa relação entre o vivido e a memória coletiva que guardaremos algumas informaçóes e descartaremos outras de nossa lembrança. Se o fato aconteceu numa situação isolada em relação ao coletivo, a tendência será o esquecimento.

O esquecimento é um dos elementos da memória (Ricœur, 2007). Quando os atletas falaram sobre suas histórias sempre o fizeram a partir de uma visão do presente. É do presente que falam do que viveram. Esquecer é um elemento intrínseco da memória. A memória não tem como guardar tudo, pois, conforme destaca Portelli (1997a, p. 33), ela tem uma condição muito mais importante do que ser um mero repositório passivo de fatos. Ela é, também, "um processo ativo de criação de significações".

Um trabalho de História Oral quer exatamente registrar essa memória, torná-la uma história contada por quem a produziu. Se a memória funciona a partir do presente ela poderá ser influenciada por inúmeros fatores, conforme adverte Tonini (2011). Não será possível resgatá-la e preservá-la na íntegra, isso é impossível, pois, de acordo com Pollak $(1989,1992)$, ao contar a sua história o indivíduo estabelece, a partir de uma seleção de fatos mais significativos, uma estrutura lógica, contínua e condensada. Essa seleção, por si só, é algo fundamental para o método da história de vida, uma vez que permite analisar e preservar aquilo que o entrevistado selecionou como elementos significativos de sua vida. Tanto o que náo foi escolhido quanto a forma como encadeia os fatos e as experiências eleitos são passíveis de serem interpretados pelo pesquisador, não com o objetivo de verificar se aquilo "realmente aconteceu", longe disso, mas com a intenção de buscar argumentos, explicaçôes e mensagens do próprio narrador.

Diante das várias considerações feitas sobre o tempo (passado, presente e futuro ou compartilhado, convencionado, transicional e das potencialidades) e seu significado subjetivo e social, é possível, entáo, reconhecer a dimensão que o relato de história de vida adquire tanto para o narrador como para o pesquisador. Passível de ser analisada numa perspectiva linear ou cíclica, dela se podem extrair elementos históricos coletivos, mas também individuais, capazes de compor uma cartografia do sujeito e do grupo ao qual ele pertence e das transformaçóes significativas ocorridas ao longo dessa trajetória.

O relato de Zé Maria, uma vez mais, nos oferece, em suas frases finais, uma mensagem sobre a própria trajetória e o movimento migratório empreendido por ele e por colegas de profissão. Nela, as dificuldades, os fracassos e as frustraçôes parecem ter um objetivo claro: revelar o triunfo e o heroísmo típico de pessoas públicas. Ao mesmo tempo, elogia nosso próprio projeto por registrar as narrativas desses profissionais, 
indicando, pois, certo prazer ao rememorar sua história de vida:

Não é tão ruim sair do país e tentar a vida fora, por um motivo ou por outro. Lá a gente aprende muitas coisas: a viver em outro continente, a conhecer culturas e modos de vida completamente diferentes, a enfrentar a vida... $\mathrm{E}$ a gente pode vencer! O Careca venceu, o Amoroso venceu, o Zé Maria venceu graças a Deus... apesar de todas as dificuldades, da saudade, da nostalgia, das contusóes, de tudo... Vocês estão de parabéns por trazer esta recordação, estas experiências. Experiências que foram, para a maioria, na minha opiniáo, extremamente positivas. Registrá-las é um tesouro. (José Marcelo Ferreira, 2013).

Nesse jogo entre lembrança e esquecimento, provavelmente, alguns fatos traumáticos não foram compartilhados. Esqueceram-se ou não quiseram contar. Nosso objetivo náo era buscar a verdade, pelo contrário, estávamos ali para ouvi-los, para registrar a memória deles e, consequentemente, preservar elementos importantes de suas experiências no futebol.

Essas histórias apontam para uma situação em que mesmo que o indivíduo obedeça a determinações próprias, subjetivas e inconscientes, as instâncias sociais e culturais que o cercam apontam para a encruzilhada que o sujeito vive no que concerne a sua vida pessoal e social. O pesquisador deve estar ciente que o entrevistado conta a verdade dele (Bosi, 2003) e do mesmo modo pode-se supor que se houver algum tipo de deformação que ela não tenha sido produzida para a posteridade (Bloch, 2001). Afinal, conforme aponta Portelli (1996, p. 62), mesmo que os fatos não tenham acontecido de tal modo como foi narrado, o que importa é que foi "contado de modo verdadeiro".

\section{Considerações finais}

Para finalizar este texto, queremos recuperar duas perguntas feitas na introdução do artigo e que somente podem ser respondidas após as reflexóes acerca dos elementos presentes nas entrevistas realizadas e que nos conduziram a pensar sobre o próprio método da História Oral. As duas perguntas guardadas para este espaço: De que maneira as memórias de atletas/futebolistas contribuem para o debate acadêmico da HO? E, por sua vez, de que maneira a $\mathrm{HO}$ contribui para o campo de estudos sobre esporte?

Se até os anos 1990 havia uma grande desconfiança com a HO (Ferreira, 1998b), as três décadas seguintes mostraram-se diferentes. Houve a organização da Associação Brasileira de História Oral (ABHO) e da entidade internacional similar (IOHA), a promoção de encontros acadêmicos internacionais, nacionais e estaduais, bem como a criação de revistas (a revista História Oral, em especial) e de dossiês voltados para essa discussáo. Desse modo, a História Oral consolidou-se como uma técnica capaz de 
produzir fontes, bem como método de pesquisa que organiza uma investigação e um conjunto de entrevistas que se quer registrar e analisar.

A consolidação do campo ocorreu concomitantemente com o desenvolvimento de inúmeras pesquisas de distintas áreas do conhecimento que se valiam da $\mathrm{HO}$, fosse como uma fonte complementar, fosse como uma fonte preferencial, a tal ponto que hoje ninguém questiona mais a validade da HO. Nesse sentido, cabe destacar que ela tem exercido papel de suma importância para a produção, tanto de novos olhares sobre temas consagrados da literatura acadêmica, quanto na constituiçáo de novos saberes sobre questóes que compóem o tempo presente. Mais do que isso, os debates por ela proporcionados estão se desdobrando na formação de novas áreas do saber, como a História Pública.

Um dos temas com os quais a $\mathrm{HO}$ tem trabalhado a partir deste milênio é exatamente o esporte. Nesse sentido, ela tem contribuído de distintas maneiras. Em primeiro lugar, pela valorização dos discursos de indivíduos e coletivos que só recentemente têm sido contemplados pelas Ciências Humanas. Por mais que se fizessem pesquisas sobre esportes, poucos eram os atletas e demais profissionais cujas vozes eram consideradas como centrais dentro da história que estava sendo contada. Os jornais, nesse sentido, sempre tiveram, e ainda têm, a primazia enquanto fonte para essa produção, mesmo que fosse para reproduzir falas de esportistas.

Nesse sentido, em segundo lugar, embora seja óbvio, sua contribuição se dá exatamente por ter outras finalidades e procedimentos em contraponto com o jornalismo esportivo. Há rigor metodológico. Dessa forma, entrevistas são planejadas dentro de um projeto de pesquisa de $\mathrm{HO}$, visando a discussáo de determinados temas, enquanto a imprensa, em geral, tem um interesse fugaz, ligado a factualismos, efemérides e atletas isoladamente, ou mesmo ligadas a questóes da ordem do dia, sem se aprofundar nos registros feitos. Nesta dinâmica de perguntar, ouvir e interpretar não se pode esquecer que "uma entrevista é sempre uma lição de aprendizagem" (Portelli, 2001, p. 20).

Nesse compasso, há que se considerar, em terceiro lugar, a abordagem ética e muito mais respeitosa possibilitada pelo fazer da História Oral, e, em quarto, a noção de comunidade que ela permite exatamente por trabalhar com a construçáo de narrativas baseadas em memórias e identidades de indivíduos, ainda que eventualmente eles não tenham consciência de que formam uma coletividade. Uma quinta contribuição, por conseguinte, é exatamente o interesse e a capacidade de ela trabalhar com temas ou relegados ou ainda espinhosos para o jornalismo esportivo, tais como: racismo, xenofobia, machismo, LGBTfobia, entre outros. ${ }^{8}$

Por fim, uma sexta maneira de contribuir é o fato de trabalhar com a subjetividade. Sendo assim, seu interesse está muito além do registro de memórias sobre fatos esportivos passados, seja a participaçáo de atletas em megaeventos, sejam seus grandes

Nos últimos anos, é notável uma mudança nesse sentido por parte do jornalismo esportivo. Não obstante, a abordagem, por vezes, é superficial e inapropriada do ponto de vista acadêmico. 
feitos esportivos. O registro das experiências e dos significados atribuídos pelas próprias trajetórias, não só esportivas, mas também pessoais, oferece uma profundidade narrativa que poucas fontes podem possibilitar. Para tanto, a prática de pesquisa dos historiadores (não só historiadores de formação, é claro) orais é fundamental para a produção com essa abordagem e densidade.

No exercício inverso, qual seja o de refletir sobre a colaboração dos estudos sobre esporte para a $\mathrm{HO}$, trazemos algumas especulaçôes fruto de nossas próprias pesquisas, sejam aquelas desenvolvidas individualmente em pós-graduação, seja aquela elaborada coletivamente e aqui descrita. É sabido que a $\mathrm{HO}$ constituiu-se internacionalmente em um período histórico em que se buscava registrar histórias e memórias de grupos sociais minoritários e marginalizados pela historiografia e pela história oficial. No Brasil, não foi diferente, ainda que a experiência do Centro de Pesquisa e Documentação de História Contemporânea do Brasil da Fundação Getúlio Vargas (CPDOC/FGV), a linha mais tradicional de $\mathrm{HO}$ no país, diga-se, esteja vinculada à produçáo de entrevistas com grandes figuras da história brasileira, tais como presidentes, ministros e líderes da classe política, econômica e jurídica.

Mesmo levando isso em consideraçáo, encontramos, particularmente, dificuldades no fazer da $\mathrm{HO}$, mais propriamente ao entrevistar futebolistas consagrados. Se, por um lado, tínhamos um material farto para pesquisa prévia do entrevistado, por outro havia o desafio de registrar uma entrevista que quebrasse com um padrão narrativo já reproduzido tanto na imprensa, quanto, às vezes, em biografias, autobiografias e documentários. Personalidades têm, por óbvio, vidas públicas e costumam apresentar um discurso já cristalizado ou mesmo épico das próprias trajetórias pessoais, mas sobretudo profissionais. Dado o caráter espetacular que o esporte alcançou desde pelo menos a metade do século XX, esportistas de grandes competiçóes, sejam elas de modalidades individuais ou coletivas, passaram a constituir cada vez mais um grupo social seleto e consagrado.

Nesse sentido, não somente a realização das entrevistas aparentam ser desafiadoras, mas também o contato e o convencimento do registro de suas histórias, memórias e experiências a pesquisadores acadêmicos, os quais, por sua vez, têm sido um agente novo e "concorrente" nesse universo. Em nossa experiência, tivemos na maioria dos casos que lidar com seus agentes, empresários e/ou assessores. A negociação, por vezes, era somente com esses profissionais, sem que o possível entrevistado soubesse de nosso interesse. Em um caso, em especial, ocorrido com Denilson, então atleta profissional do São Paulo F.C., ficou nítido no encontro que o entrevistado mal sabia do projeto, das motivaçóes e dos objetivos de nossa pesquisa. Se isso náo bastasse, na primeira entrevista com ele realizada, tivemos a presença constante do assessor de imprensa do clube, em pé, próximo ao atleta, visivelmente vigiando cada palavra enunciada pelo jogador. Trata-se de uma situaçáo em que náo tivemos controle nem sobre o local nem sobre as pessoas presentes no ato da gravação. São pontos, pois, em que a $\mathrm{HO}$ 
certamente carece de reflexão e proposição de alternativas teórico-metodológicas.

Para além do debate acadêmico, a produção de entrevistas em História Oral pode ser uma excelente forma de se comunicar com um público mais amplo. Nesse sentido, projetos como o "Memórias de Boleiros" aqui apresentado deveriam se proliferar de modo a ampliar o acervo de entrevistas e mantê-las armazenadas e disponíveis para consulta. Não há como negar, também, que novas tecnologias podem e têm contribuído para a produçáo de novas fontes orais. A pandemia da covid-19 acelerou o uso dos recursos digitais para a gravação de entrevistas - inclusive transmitidas instantaneamente - rompendo barreiras geográficas. Isso, no entanto, necessita de análises mais profundas e lança novos desafios para a História Oral.

\section{Referências}

AZEVEDO, Clara; ALFONSI, Daniela. A patrimonialização do futebol: notas sobre o Museu do Futebol. Revista de História, São Paulo, n.163, p. 275-292, 2010.

BLOCH, Marc. A apologia da história ou o ofício do historiador. Rio de Janeiro: Jorge Zahar Editor, 2001.

BOSI, Ecléa. O tempo vivo da memória. São Paulo: Ateliê Editorial, 2003.

BOSI, Ecléa. Memória e sociedade. 14. ed. São Paulo: Companhia das Letras, 2007.

DAMO, Arlei Sander. Do dom à profissão: formação de futebolistas no Brasil e na França. São Paulo: Hucitec/ANPOCS, 2007.

FERREIRA, Marieta de Moraes. Desafios e dilemas da história oral nos anos 90: o caso do Brasil. História Oral, v. 1, p. 19-30, 1998a.

FERREIRA, Marieta de Moraes (Coord.). Entre-vistas: abordagens e usos da história oral. Rio de Janeiro: FGV, 1998b

FERREIRA, Marieta de Moraes. História, tempo presente e história oral. Topoi, Rio de Janeiro, v. 3, n. 5, p. 314-332, 2002.

GIGLIO, Sérgio Settani. COI $x$ FIFA: a história política do futebol nos Jogos Olímpicos. Tese (Doutorado em Ciências) - Escola de Educação Física e Esporte, USP, São Paulo, SP, 2013.

GIGLIO, Sérgio Settani. A história politica do futebol olímpico (1894-1988). São Paulo: Intermeios/Fapesp, 2018.

GIGLIO, Sérgio Settani; TONINI, Marcel Diego. História oral e futebol. In: MAGALHĀES, Lívia Gonçalves; TEIXEIRA, Rosana da Câmara (Org.). Futebol na sala de aula: jogadas, dribles, passes, esquemas táticos e atuaçóes para o ensino de Ciências Sociais e de História. Niterói: Eduff, [2021?]. No prelo.

HALBWACHS, Maurice. A memória coletiva. São Paulo: Centauro, 2006.

MAGNANI, José Guilherme Cantor. De perto e de dentro: notas para uma etnografia urbana. 
Revista Brasileira de Ciências Sociais, São Paulo, v. 17, n. 49, p. 11-29, 2002.

MAGNANI, José Guilherme Cantor. Etnografia como prática e experiência. Horizontes Antropológicos, Porto Alegre, v. 15, n. 32, p. 129-156, 2009.

MEIHY, José Carlos Sebe Bom. Manual de história oral. 5. ed. São Paulo: Loyola, 2005.

MEIHY, José Carlos Sebe Bom; HOLANDA, Fabíola. História oral: como fazer, como pensar. São Paulo: Contexto, 2007.

MORAES, Enny Vieira. O Museu do Futebol e uma história parcial; ou não há futebol feminino no Brasil? Recorde, Rio de Janeiro, v.2, n. 1, 2009.

NORA, Pierre. Entre memória e história: a problemática dos lugares. Projeto História, São Paulo, n. 10, p. 7-28, dez. 1993.

OLIVEIRA, Roberto Cardoso. O trabalho do antropólogo. 2. ed. Brasília: Paralelo 15; São Paulo: Editora Unesp, 2006.

ORTIZ, Renato. Mundialização e cultura. São Paulo: Brasiliense, 2000.

PASSERINI, Luisa. A memória entre política e emoção. São Paulo: Letra e Voz, 2011.

POLLAK, Michael. Memória, Esquecimento, Silêncio. Estudos Históricos, Rio de Janeiro, v. 2, n. 3, p. 3-15, 1989.

POLLAK, Michael. Memória e identidade social. Estudos Históricos, Rio de Janeiro, v. 5, n.10, p. 200-215, 1992.

PORTELLI, Alessandro. A filosofia e os fatos: narração, interpretação e significado nas memórias e nas fontes orais. Tempo, Rio de Janeiro, v. 1, n. 2, p. 59-72, 1996.

PORTELLI, Alessandro. Ensaios de história oral. São Paulo: Letra e Voz, 2010.

PORTELLI, Alessandro. História oral como gênero. Projeto História, São Paulo, n. 22, p. 9-36, 2001.

PORTELLI, Alessandro. O que faz a história oral diferente. Projeto História, São Paulo, n. 14, p. 25-39, 1997a.

PORTELLI, Alessandro. Tentando aprender um pouquinho. Algumas reflexóes sobre a ética na História Oral. Projeto História, São Paulo, n. 15, p. 13-49, 1997 b.

RIAL, Carmen. Rodar: a circulação dos jogadores de futebol brasileiros no exterior. Horizontes Antropológicos, Porto Alegre, v. 14, n. 30, p. 21-65, 2008.

RICEEUR, Paul. A memória, a história, o esquecimento. Campinas: Editora da Unicamp, 2007.

RUBIO, Katia. Medalhistas olímpicos brasileiros: memórias, histórias e imaginário. São Paulo: Casa do Psicólogo/Fapesp, 2006.

SANTOS, Myrian Sepúlveda dos. Sobre a autonomia das novas identidades coletivas: alguns problemas teóricos. Revista Brasileira de Ciências Sociais, São Paulo, v. 13, n. 38, p. 151-165, out. 1998.

SANTOS, Myrian Sepúlveda dos. Memória coletiva, trauma e cultura: um debate. Revista USP, São Paulo, n. 1, p. 51-68, jun./jul./ago. 2013. 
TOLEDO, Luiz Henrique de. Presente etnográfico e "presente museográfico": o caso do Museu do Futebol visto por um antropólogo urbano. Cadernos de Campo, Sáo Paulo, v. 28, n. 1, p. 249-272, 2019.

TONINI, Marcel Diego. Além dos gramados: história oral de vida de negros no futebol brasileiro (1970-2010). Dissertação (Mestrado em História Social) - Faculdade de Filosofia, Letras e Ciências Humanas, USP, São Paulo, SP, 2011.

TONINI, Marcel Diego. Dentro e fora de outros gramados: histórias orais de vida de futebolistas brasileiros negros no continente europeu. Tese (Doutorado em História) - Faculdade de Filosofia, Letras e Ciências Humanas, USP, São Paulo, SP, 2016.

TONINI, Marcel Diego. "Essa é uma realidade": os racismos vividos e narrados por negros em várias áreas de atuação no futebol brasileiro. In: GIGLIO, Sérgio Settani; PRONI, Marcelo Weishaupt (Org.). O futebol nas ciências humanas no Brasil: Campinas: Editora da Unicamp, 2020 .

WENZEL, Marianne; MUNHOZ, Mauro. Museu do Futebol: arquitetura e requalificação no Estádio do Pacaembu. São Paulo: Romano Guerra, 2012.

\section{Fontes orais}

AMÂNCIO, Ebert Willian (Betão) [37 anos]. [fev. 2014]. Entrevistadores: Aira Bonfim, Bruna Gottardo, Marcel Diego Tonini. São Paulo, SP, 27 fev. 2014.

DIAS, Djalma Feitosa (Djalminha) [50 anos]. [jul. 2012]. Entrevistadores: Marcel Diego Tonini, Sérgio Settani Giglio. Rio de Janeiro, RJ, 12 jul. 2012.

FERREIRA, José Marcelo (Zé Maria) [47 anos]. [abr. 2013]. Entrevistadores: Aira Bonfim, Bruna Gottardo, Marcel Diego Tonini, Sérgio Settani Giglio. São Paulo, SP, 24 abr. 2013.

NEVES, Denilson Pereira (Denilson) [33 anos]. [fev. e maio 2014]. Entrevistadores: Ademir Takara, Bruna Gottardo, Marcel Diego Tonini, Yurick Pilon. São Paulo, SP, 11 fev.; 9 maio 2014.

OLIVEIRA FILHO, Antônio de (Careca) [60 anos]. [out. 2012]. Entrevistadores: Bruna Gottardo, Marcel Diego Tonini. Campinas, SP, 2 out. 2012.

PAULINO, Evair Aparecido (Evair) [56 anos]. [maio 2013]. Entrevistadores: Bruna Gottardo, Paulo Henrique do Nascimento. São Paulo, SP, 27 maio 2013.

PRATES, Wendel (Nenê) [34 anos]. [abr. 2013]. Entrevistadores: Aira Bonfim, Bruna Gottardo, Paulo Henrique do Nascimento. São Paulo, SP, 3 abr. 2013.

SANTOS, Márcio Amoroso dos (Amoroso) [47 anos] [ago. 2013]. Entrevistadores: Aira Bonfim, Bruna Gottardo, Marcel Diego Tonini. São Paulo, SP, 22 ago. 2013.

Recebido em 01/05/2021.

Aprovado em 22/07/2021. 
Contribuiçóes dos autores: Giglio: análise dos dados, concepção da pesquisa, gravação de depoimentos, pesquisa bibliográfica, pesquisa documental e redação; Tonini: análise dos dados, concepção da pesquisa, gravaçáo de depoimentos, pesquisa bibliográfica, pesquisa documental e redação.

Fonte de financiamento: Núcleo de Apoio à Pesquisa - Núcleo Interdisciplinar de Pesquisas sobre Futebol e Modalidades Lúdicas (Ludens/USP).

Conflitos de interesse: nada a declarar. 